\title{
Fibrotic liver microenvironment promotes DII4 and SDF-1-dependent T-cell lineage development
}

\author{
Zheng Gong ${ }^{1,2}$, Bingxue Shang ${ }^{1}$, Yunpeng Chu', Xiaodong Chen², Qing Li ${ }^{2}$, Keli Liu², Yongjing Chen', Yin Huang $\mathbb{B}^{2}$,

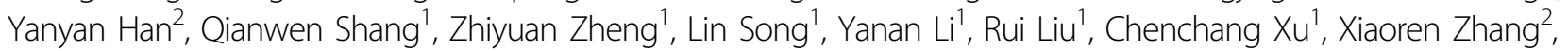 \\ Baochi Liư ${ }^{3}$ Luowei Wang ${ }^{4}$, Changshun Shao (1), Ying Wang ${ }^{2}$ and Yufang Shi id,
}

\begin{abstract}
The reconstitution of the T-cell repertoire and quantity is a major challenge in the clinical management of HIV infection/AIDS, cancer, and aging-associated diseases. We previously showed that autologous bone marrow transfusion (BMT) via the hepatic portal vein could effectively restore CD4 ${ }^{+} \mathrm{T}$-cell count in AIDS patients also suffering from decompensated liver cirrhosis. In the current study, we characterized T-cell reconstitution in a mouse model of liver fibrosis induced by $\mathrm{CCl}_{4}$ and found that T-cell reconstitution after BMT via hepatic portal vein was also greatly enhanced. The expression of D/l4 (Delta-like 4), which plays an important role in T-cell progenitor expansion, was elevated in hepatocytes of fibrotic livers when compared to normal livers. This upregulation of D/l4 expression was found to be induced by TNFa in an NFkB-dependent manner. Liver fibroblasts transfected with DII4 (LF-D\|4) also gained the capacity to promote T-cell lineage development from hematopoietic stem cells (HSCs), resulting in the generation of DN2 (CD4 and CD8 DN 2) and DN3 T-cell progenitors in vitro, which underwent a normal maturation program when adoptively transferred into Rag-2 deficient hosts. We also demonstrated a pivotal role of SDF-1 produced by primary liver fibroblasts (primary LF) in T-lineage differentiation from HSCs. These results suggest that DII4 and SDF-1 in fibrotic liver microenvironment could promote extrathymic T-cell lineage development. These results expand our knowledge of T-cell development and reconstitution under pathological conditions.
\end{abstract}

\section{Introduction}

Reconstitution of $\mathrm{T}$ cells is a major clinical challenge in patients suffering from HIV/AIDS, cancer, and agingassociated diseases. T-cell deficiency is a cardinal feature of aging or HIV infection and underlies susceptibility to

Correspondence: Luowei Wang (wangluoweimd@126.com) or Changshun Shao (shaoc@suda.edu.cn) or Ying Wang (yingwang@sibs.ac.cn) or Yufang Shi (yfshi@suda.edu.cn)

${ }^{1}$ The First Affiliated Hospital of Soochow University, Institutes for Translational Medicine, State Key Laboratory of Radiation Medicine and Protection, Key Laboratory of Stem Cells and Medical Biomaterials of Jiangsu Province, Soochow University Medical College, Suzhou, China

${ }^{2}$ Key Laboratory of Tissue Microenvironment and Tumor, Institute of Health Sciences, Shanghai Institutes for Biological Sciences, Chinese Academy of

Sciences, University of Chinese Academy of Sciences, Shanghai, China

Full list of author information is available at the end of the article.

Edited by H.-U. Simon infectious microorganisms and malignancies ${ }^{1,2}$. In cancer patients, chemotherapy or preparative regimens for bone marrow transplantation result in severe and protracted lymphopenia, and the recovery of T-cell populations is often delayed compared to that of myeloid, NK, or B cells ${ }^{3}$. Moreover, T-cell function often remains compromised even after lymphocyte numbers are restored to normal level, likely due to a reduced $\mathrm{T}$-cell clonal diversity $^{4-6}$. In AIDS patients, although the viral loads in peripheral blood can be kept under control after antiretroviral therapy, their health conditions can still deteriorate with dramatically decreased $\mathrm{CD} 4^{+} \mathrm{T}$-cell count. Stable reconstitution of $\mathrm{CD} 4^{+} \mathrm{T}$-cell number and functional clonality, with complete suppression of viral replication and elimination of viral reservoirs, has been

\section{(c) The Author(s) 2019}

(c) (i) Open Access This article is licensed under a Creative Commons Attribution 4.0 International License, which permits use, sharing, adaptation, distribution and reproduction cc) in any medium or format, as long as you give appropriate credit to the original author(s) and the source, provide a link to the Creative Commons license, and indicate if changes were made. The images or other third party material in this article are included in the article's Creative Commons license, unless indicated otherwise in a credit line to the material. If material is not included in the article's Creative Commons license and your intended use is not permitted by statutory regulation or exceeds the permitted use, you will need to obtain permission directly from the copyright holder. To view a copy of this license, visit http://creativecommons.org/licenses/by/4.0/. 
the ultimate goal of AIDS therapy ${ }^{7}$. We previously showed that administration of autologous bone marrow transfusion (BMT) via the hepatic portal vein could effectively restore $\mathrm{CD} 4^{+} \mathrm{T}$-cell count in AIDS patients who were also suffering from decompensated liver cirrhosis ${ }^{8,9}$. This observation indicates a possibility that the cirrhotic liver microenvironment may possess lymphopoiesis supportive activity that can direct autologous hematopoietic stem/ progenitor cells to undergo differentiation toward early $\mathrm{T}$ lineage.

T-cell development occurs in multiple discrete steps and is controlled by complex regulatory mechanisms ${ }^{10}$. Thymocytes can be divided into the categories of doublenegative (DN), immature double-positive (DP), and mature single-positive (SP) cells based on their expression of $\mathrm{CD} 4$ and/or $\mathrm{CD} 8^{11}$. In the mouse, DN thymocytes are typically classified, according to the surface expression of CD25 and CD44 or CD117 (c-kit), into DN1-DN4 subsets. CD4 $4^{+} \mathrm{CD} 8^{+}$DP thymocytes are subjected to positive and negative selection in the thymus ${ }^{12}$. Following these selections, mature, CD4 or CD8 SP thymocytes are exported from the thymus to establish the pool of self-restricted and functional $\mathrm{T}$ cells in the periphery ${ }^{13}$.

In the current study, we showed that liver fibrosis induced by $\mathrm{CCl}_{4}$ in a murine model could promote $\mathrm{T}$-cell reconstitution after BMT via hepatic portal vein. Surprisingly, Dll4, an important factor in T-cell progenitor development, was upregulated in hepatocytes of the fibrotic tissues. We also showed that liver fibroblasts expressing Delta-like 4 (LF-Dll4) gained the capacity to induce a normal program of early $\mathrm{T}$-cell development from hematopoietic stem cells (HSCs). These DN2 and $\mathrm{DN} 3 \mathrm{~T}$-cell progenitors generated in vitro were found to follow a normal maturation program in the thymus of Rag-2 deficient hosts when adoptively transferred. We also demonstrated a pivotal role of stromal cell-derived factor-1 (SDF-1)/chemokine CXC chemokine ligand 12 (CXCL12)/pre-B-cell growth stimulating factor in primary LF-Dll4 in directing HSC differentiation into T lineage. These results suggested that Dll4 and SDF-1 in the fibrotic liver microenvironment promote early $\mathrm{T}$-cell development and maturation.

\section{Results}

Enhanced T-cell reconstitution by BMT in mice suffering from $\mathrm{CCl}_{4}$-induced liver fibrosis

We previously reported that autologous BMT via the hepatic portal vein could effectively reconstitute peripheral $\mathrm{CD}_{4}^{+} \mathrm{T}$-cell counts and hepatic function in splenectomized AIDS patients with decompensated liver cirrhosis $^{8,9}$. To recapitulate this observation in an experimental setting, we induced liver fibrosis with $\mathrm{CCl}_{4}$ in combination with splenectomy in CD45.2/C57BL/6J mice and examined the subsequent $\mathrm{T}$-cell reconstitution. Splenectomy, by spleen ligation and removal, was carried out immediately after CD45.1/C57BL/6J bone marrow cells (BMCs) were transplanted in control and $\mathrm{CCl}_{4}$ treated mice (Fig. 1a). Flow cytometry showed significant differences of $\mathrm{T}$-lineage populations between the $\mathrm{CCl}_{4}$ treated and the control groups in the thymus and peripheral blood 28 days after BMT. Donor cells were identified by $\mathrm{CD} 45.1 . \quad \mathrm{CD} 44^{+} \mathrm{CD} 25^{-}, \mathrm{CD} 44^{+} \mathrm{CD} 25^{+}$, $\mathrm{CD} 44^{-} \mathrm{CD} 25^{+}$, and $\mathrm{CD} 44^{-} \mathrm{CD} 25^{-}$marked DN1-DN4 Tlineage cell populations, respectively. $\mathrm{CD} 4^{+} \mathrm{CD} 8^{-}$, $\mathrm{CD} 4^{-} \mathrm{CD}^{+}, \mathrm{CD}^{+} \mathrm{CD}^{+}$, and $\mathrm{CD} 4^{-} \mathrm{CD} 8^{-}$in the thymus indicated CD4SP, CD8SP, DP, and DN T-lineage populations, respectively. The percentages and absolute numbers of both DN3 and DP cells were greater in the $\mathrm{CCl}_{4}$ treated group than in the control group (Fig. 1b, c). In peripheral blood, a noticeable increase in the percentage and absolute numbers of $\mathrm{CD} 4^{+} \mathrm{T}$-cell population was also observed in the $\mathrm{CCl}_{4}$-treated group over the control group (Fig. 1d). In contrast, such increase was not observed in the liver (Supplementary Fig. 1). The endogenous cells in the recipient mice $\left(\mathrm{CD} 45.2^{+}\right)$appeared to be unaffected by fibrosis after irradiation and BMT (Supplementary Fig. $2 \mathrm{a}-\mathrm{c}) . \mathrm{CCl}_{4}$ treatment alone also had no effect on the total number of thymocytes (Supplementary Fig. 3a, b).

To eliminate possible influences by host $\mathrm{T}$ cells and splenectomy, which may affect donor T-cell reconstitution in recipient mice after BMT, on T-lymphopoiesis under the fibrotic microenvironment, we also transplanted CD45.1 congenic BMCs into Rag2 ${ }^{-/-}$CD45.2/ C57BL/6J hosts without splenectomy and obtained similar results (Fig. 2a-d). Flow cytometric analysis revealed significant differences of T-lineage-cell populations between the $\mathrm{CCl}_{4}$-treated and control groups in the thymus, peripheral blood, and spleen. The DN3 and DP Tlineage populations were greater in the $\mathrm{CCl}_{4}$-treated group than in the control group (Fig. $2 \mathrm{~b}, \mathrm{c}$ ). In the $\mathrm{CCl}_{4}$ treated group, $\mathrm{CD} 4^{+}$T-cell percentage and absolute numbers were also higher in both peripheral blood and splenic $\mathrm{CD}^{+} \mathrm{T}$-cell subsets than in the control group (Fig. 2d).

These data suggest that the mouse model based on $\mathrm{CCl}_{4}$ treatment and splenectomy could recapitulate some of the clinical features manifested in autologous bone marrowtreated AIDS patients with fibrotic livers, and the fibrotic liver microenvironment may play an important role in $\mathrm{T}$ cell reconstitution after BMT via the hepatic portal vein.

\section{DII4 expressed in hepatocytes of fibrotic liver promotes T- cell development}

Since Notch signaling is essential for T-lymphoid commitment and is required for the progression through the DN stage $\mathrm{e}^{14-18}$, we hypothesized that Notch signaling may contribute to the enhanced $\mathrm{CD} 4^{+} \mathrm{T}$-cell 

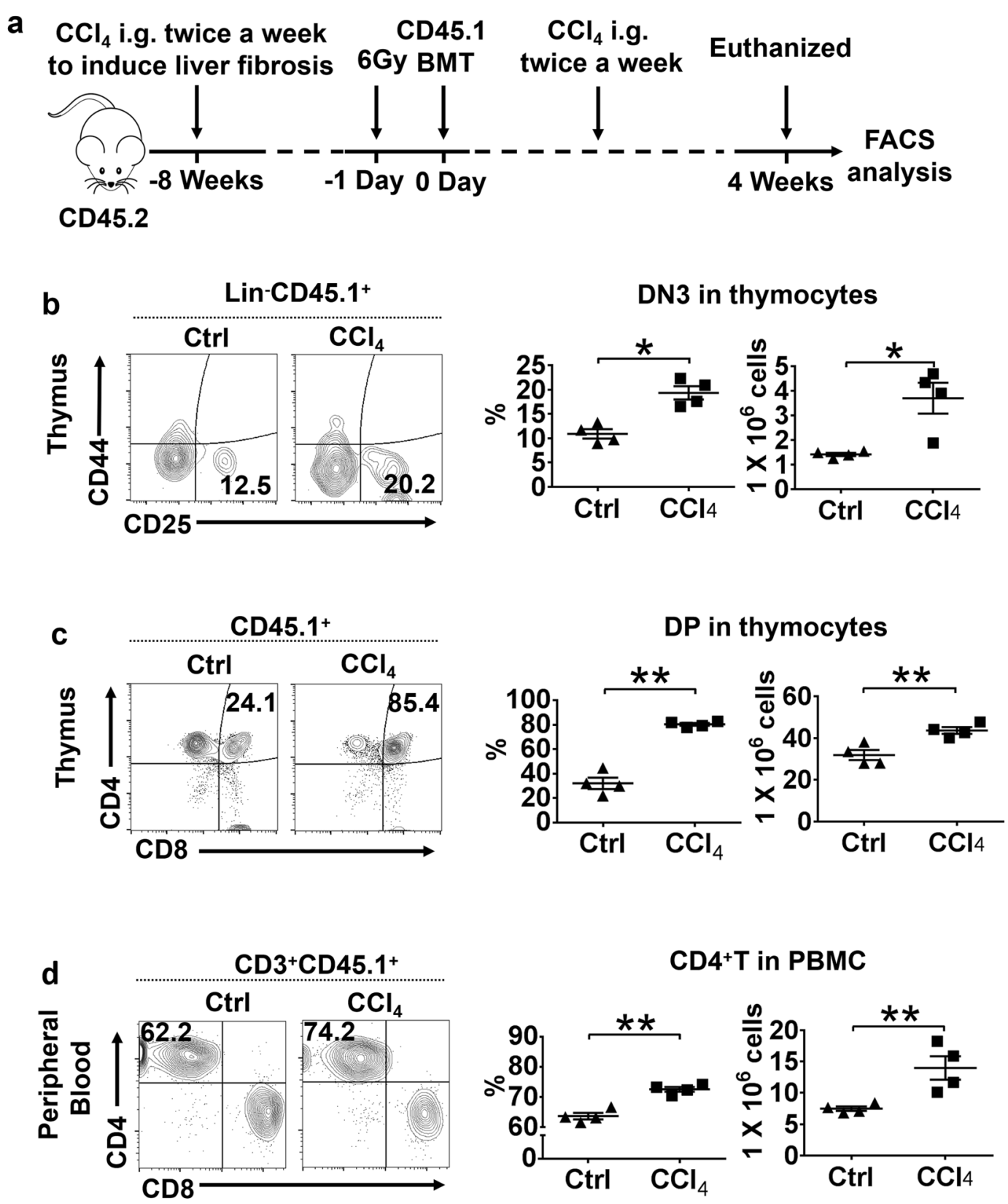

Fig. 1 Liver fibrosis induced by $\mathrm{CCl}_{4}$ promotes T-cell reconstitution. a Schematic representation of the experimental procedures using $\mathrm{CCl}_{4}-$ induced liver fibrosis followed by BMT in a mouse model. b Flow cytometric analysis for the expression of CD25 and CD44 on thymocyte for DN1-DN4 stages of the T-cell development in the thymus on day 28 after CD45.1 BMT through the hepatic portal vein. $\mathbf{c}$ Flow cytometric analysis for the expression of CD4 and CD8 in thymocytes for the DP and SP stages of T-cell development, on day 28 after CD45.1 BMT. d Flow cytometric analysis for the expression of CD4 and CD8 on PBMCs for $\mathrm{CD}^{+}$and $\mathrm{CD} 8^{+}$T cells in peripheral blood on day 28 after CD45.1 BMT. The results are presented as mean \pm S.E.M. Statistical significance was determined by Student's $t$ test. Significance between samples is indicated in the figures as follows: ${ }^{*} P<0.05 ;{ }^{*} P<0.01$

development in $\mathrm{CCl}_{4}$-induced liver fibrosis. Indeed, we found that the mammalian Notch ligand Dll4 expression was gradually increased in the liver with increased duration of $\mathrm{CCl}_{4}$ treatment (Fig. 3a). To determine the cellular source of Dll4 in the fibrotic liver tissue, we stained liver sections of $\mathrm{CCl}_{4}$-treated mice by immunofluorescence
(Fig. 3b and Supplementary Fig. 4a), and found that Dll4 was expressed by hepatocytes $\left(\mathrm{CK} 18^{+}\right)$, but not by endothelial $\left(\mathrm{CD} 31^{+}\right)$or myofibroblast cells $\left(\alpha \mathrm{SMA}^{+}\right)$in fibrotic liver tissue. Interestingly, in human fibrotic liver tissues, immunohistochemistry staining showed that Dll4 colocalized with hepatocytes marked by CK18, but not 

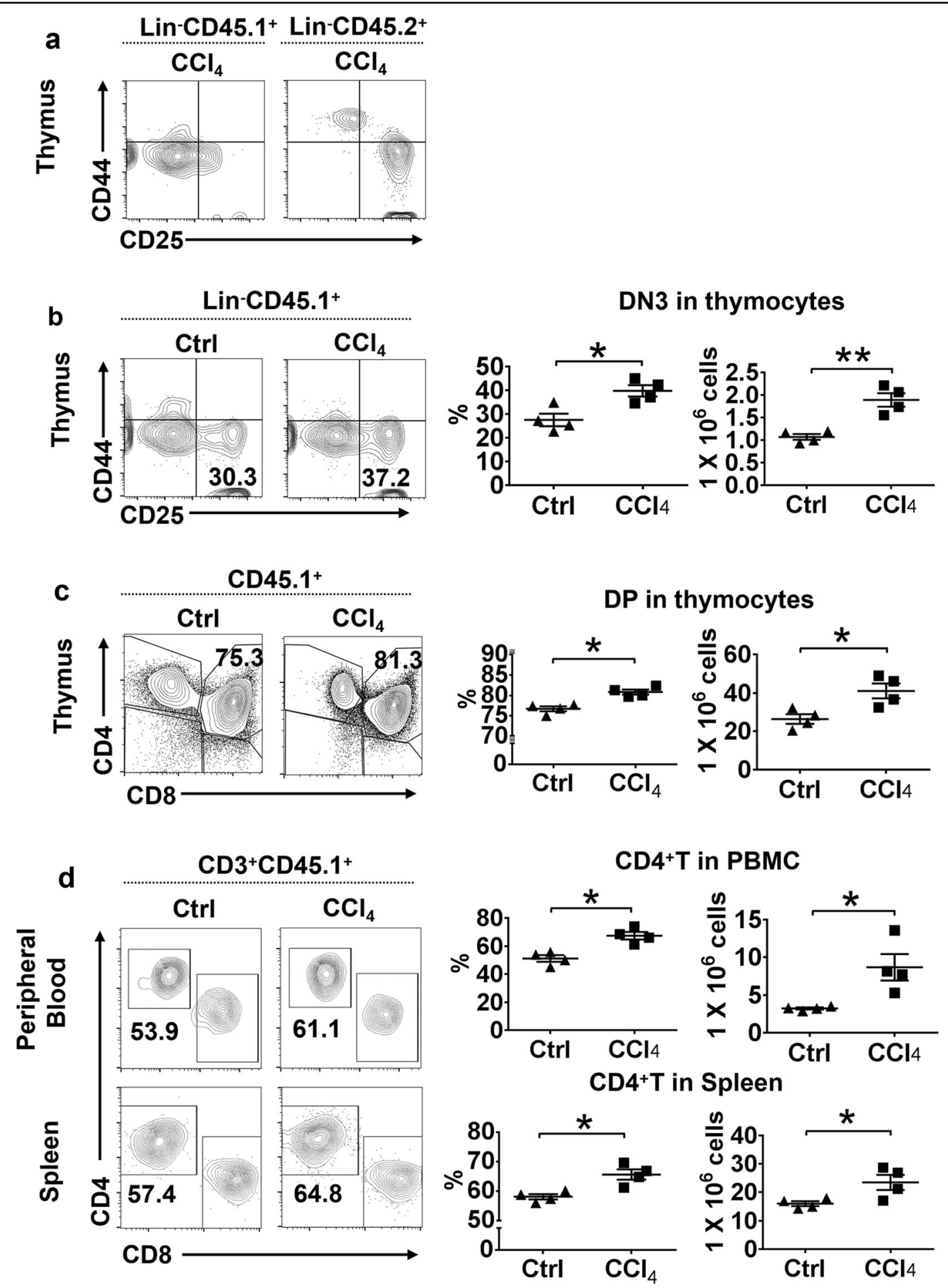

Fig. 2 Analysis of engraftment and differentiation of BMCs in Rag2 $\mathbf{2}^{-1-}$ mice. a Flow cytometric analysis for the expression of CD25 and CD44 in thymocytes on day 28 after CD45.1 BMT through the hepatic portal vein. Differentiation of CD45.1 donor cells can be detected (left). $\mathbf{b}$ Flow cytometric analysis for the expression of CD25 and CD44 on thymocytes for DN1-DN4 stages of T-cell development in thymus of Rag $2^{-1-}$ mice with and without $\mathrm{CCl}_{4}$ treatment on day 28 after CD45.1 BMT. c Flow cytometric analysis for the expression of CD4 and CD8 in thymocytes for DP and SP

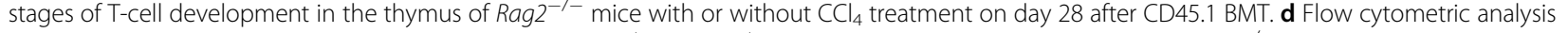
for the expression of CD4 and CD8 in lymphocytes for $C D 4^{+}$and $C D 8^{+} T$ cells in peripheral blood and spleen of Rag $^{-/-}$mice with or without $C C{ }_{4}$ treatment on day 28 after CD45.1 BMT. The results are presented as mean \pm S.E.M. Statistical significance was determined by Student's $t$ test. Significance between samples is indicated in the figures as follows: ${ }^{*} P<0.05$; ${ }^{*} P<0.01$ 


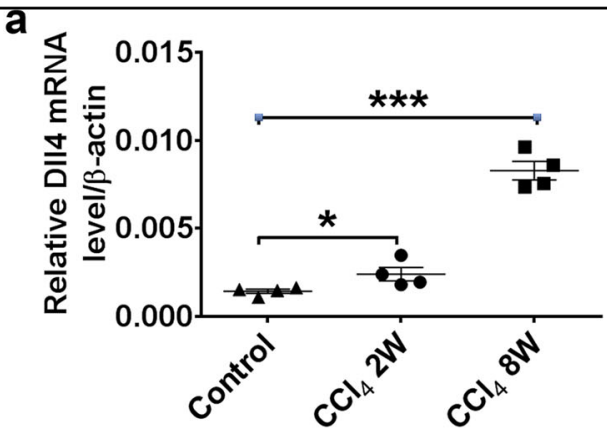

b
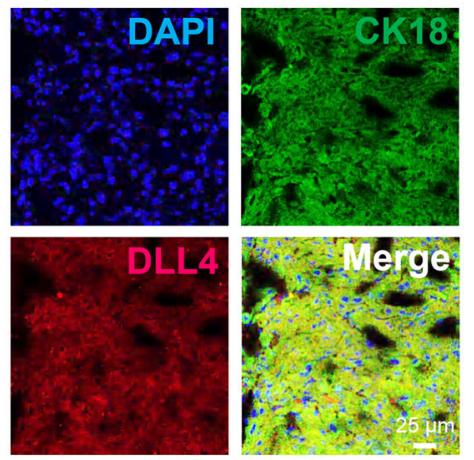

d

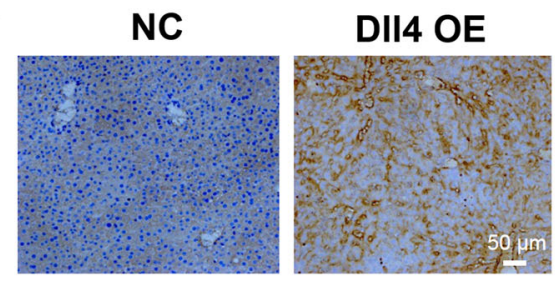

e

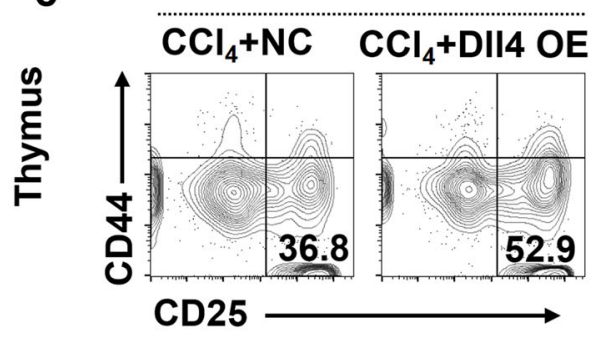

C
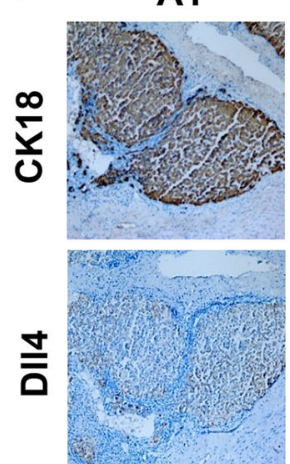

A2
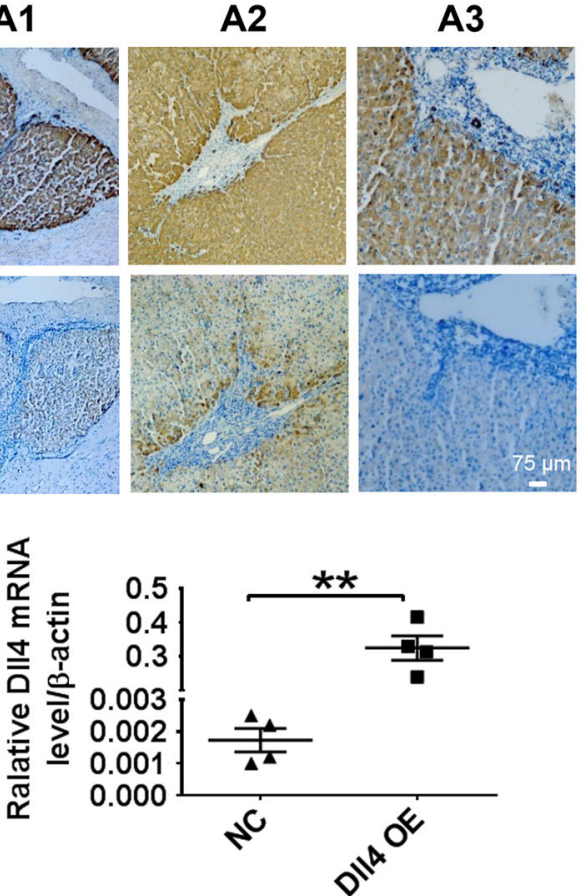

DN3 in thymocytes

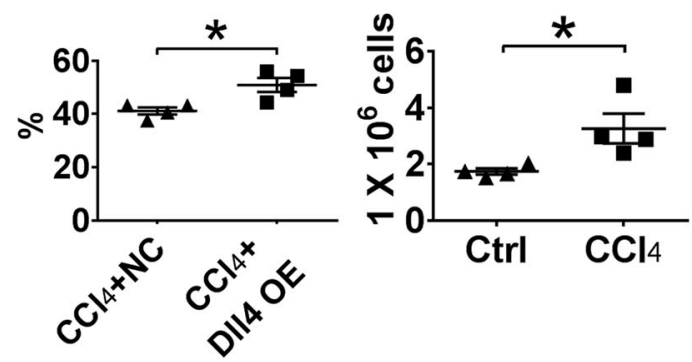

Fig. 3 Elevated DII4 expression in hepatocytes of fibrotic liver promotes T-cell lineage development. a Liver tissues from mice suffering from liver cirrhosis induced by $\mathrm{CCl}_{4}$ were collected and qRT-PCR was performed on total RNA to determine the level of DII4 mRNA. ${ }^{*} P<0.05$; ${ }^{* * *} P<0.001$ compared to the control. $\mathbf{b}$ The cell types and the levels of DII4 expression in fibrotic mouse liver tissue were examined by immunofluorescence, using DII4 and CK18-specifc antibodies. c Serial sections of liver tissue from different patients (A1-A3) suffering from AIDS and different degrees of liver cirrhosis, and immunohistochemistry analysis were employed to examine the cell types with DIl4 expression and the level of Dll4 expression change in different patients, using DII4 and CK18-specific antibodies. $\mathbf{d}$ Generation of a mouse model with ectopic DII4 expression in liver tissue by adenoviral transfection; immunohistochemistry analysis was used to examine the level of Dll4 expression between the empty vector control group and the DII4 overexpression group. Total RNA was harvested and the DII4 mRNA level was analyzed by qRT-PCR. ** $P<0.01$ compared to the empty vector control. e The expression levels of CD25 and CD44 on thymocytes were analyzed by flow cytometry in mouse liver tissues from mice with and without Dll4-overexpressing vector treatment in mice suffering from $\mathrm{CCl}_{4}$-induced liver fibrosis on day 28 after CD45.1 BMT through the hepatic portal vein. The results are presented as mean \pm S.E.M. Statistical significance was determined by Student's $t$ test. Significance between samples is indicated in the figures as follows: ${ }^{*} P<0.05 ;{ }^{*} P<0.01 ;{ }^{* *} P<0.001$ 
with endothelial cells and myofibroblasts (Fig. 3c and Supplementary Fig. 4b). We also isolated mouse primary $\mathrm{LF}$ and primary hepatocytes from $\mathrm{CCl}_{4}$-treated mice, and found that Dll4 mRNA was highly expressed in primary hepatocytes, but was barely detectable in primary LF cells (Supplementary Fig. 4c). The expression of Dll4 was low in hepatocytes of control mice. The data indicate that Dll4 was selectively upregulated in hepatocytes of fibrotic liver.

To further determine the role of Dll4 in T-cell reconstitution in vivo, we used adenoviral expression vectors to generate mice with ectopic Dll4 expression in the liver tissue (Fig. 3d). We performed flow cytometry to quantify $\mathrm{T}$ lineage in $\mathrm{CCl}_{4}$-treated Dll4 overexpression $(\mathrm{OE})$ and normal control (NC) mice after BMT via the hepatic portal vein. Dll4 ectopic expression in the liver resulted in a marked increase in DN3 percentage and absolute numbers in the thymus (Fig. 3e). However, Dll4 OE alone had no effect on the percentage and total number of thymocytes in the thymus, and lymphocytes in peripheral blood and spleen compared with control (NC) (Supplementary Fig. 5a-c). It should be noted that no increased Dll4 expression was detected in thymus (Supplementary Fig. 6a), refuting the possibility that the increase in the DN3 population was due to an alteration in thymus function.

Together, these results demonstrated that liver fibrosis could upregulate Dll4 expression in hepatocytes, and this expression of Dll4 contributes to the early stage T-cell development by promoting $\mathrm{T}$-cell progenitor development.

\section{Induction of DII4 in hepatocytes is partially NFKB- dependent}

We next determined whether the increased expression of Dll4 in fibrotic liver is associated with increased inflammation. We employed Tnfrsf $1 b^{-1-}$ mice, which is defective in response to bacterial endotoxin, LPS. Thus, wild-type (WT) and Tnfrsf $1 b^{-1-}$ C57BL/6J mice were injected with lethal doses of LPS intraperitoneally, euthanized at different time points, and their liver tissues were then assayed for Dll4 mRNA expression. We found that the induction of Dll4 mRNA expression in WT mice was rapid and reached peak expression at $1 \mathrm{~h}$ post LPS administration, and it was strongly correlated with serum TNF $\alpha$ concentration (Fig. $4 \mathrm{a}-\mathrm{c}$ ). In sharp contrast, no Dll4 induction was detected in Tnfrsf $1 b^{-1-}$ mice after LPS treatment, though there was a remarkable induction of the TNF $\alpha$ (Fig. 4a, b). This result indicates that TNF $\alpha$ signaling pathway is critical for the induction of Dll4 in hepatocytes.

The levels of TNF $\alpha$ concentration in $\mathrm{CCl}_{4}$-treated mice were significantly and persistently higher than those in $\mathrm{NC}$ mice (Supplementary Fig. 7a). To further determine the role of TNF $\alpha$ and its signaling pathway in inducing the expression of Dll4 in hepatocytes, we isolated primary hepatocytes by two-step collagenase perfusion of normal C57BL/6J liver tissues (Supplementary Fig. 8a). Primary hepatocytes treated with LPS and different cytokines: IFN $\alpha$, IL-3, IL-4, IL-12, IL-17, M-CSF, IFN $\gamma$, TNF $\alpha$, IL-1 $\beta$ or IL-15, and Dll4 mRNA expression was assessed by qRT-PCR. Among all treatments, TNFa treatment strongly induced Dll4 expression at mRNA level (Supplementary Fig. 8b). TNFa at 50 and $100 \mathrm{ng} / \mathrm{ml}$ showed the highest induction of Dll4 expression (Fig. 4d). Assay of cell surface protein expression of Dll4 by flow cytometry also revealed a 2.19 -fold increase by TNF $\alpha$ (Fig. 4e). We also used TNFaR-specific blocking antibodies at $5 \mu \mathrm{g} / \mathrm{ml}$ or NFkB inhibitor JSH-23 to determine whether TNF $\alpha \mathrm{R}$ and NFKB are involved in the induction of Dll4 mRNA. We found that blockade of TNF $\alpha$ R or inhibition of the $\mathrm{NF} \kappa \mathrm{B}$ pathway could significantly attenuate Dll4 induction by TNF $\alpha$ (Fig. 4f), $p$-value $<0.01$. These data suggested that TNF $\alpha$ signals act through TNF $\alpha$ R and the NFkB pathway to induce Dll4 expression in hepatocytes.

We then analyzed the mouse Dll4 promoter using the TRANSFAC database and identified potential binding sites for known TNF $\alpha$ inducible transcription factors. Of particular interest was a perfect consensus $\mathrm{NFKB}$ site at -2008 to $-1998 \mathrm{bp}$ upstream of the transcription start site (TSS) (Fig. 4g). We PCR-amplified a 3.04-kb fragment of the mouse promoter region and cloned it into the pGL3-basic reporter vector. This construct, referred to as WT, occurs $2728 \mathrm{bp}$ upstream and $325 \mathrm{bp}$ downstream of the TSS. We also constructed Mut1 version possessing a 3-bp mutation in the putative NFKB site of the WT promoter designed to block binding of $\mathrm{NF} \mathrm{B}$ proteins (GGGAGTCTCC to TCTAGTCTCC), and Mut2 version with 1-bp mutation in the putative NFkB site of the WT promoter change to another kind of NFkB binding site sequence (GGGAGTCTCC to TCTAGTCCCC), and then generated a truncated version of the promoter $(-1975$ to $+58 \mathrm{bp}$ ) lacking the $\mathrm{NF \kappa} B$ site. When transfected into primary hepatocytes and assayed for luciferase activity in control and TNF $\alpha$-treated cells, the Mut2 and WT promoter was strongly responsive to TNF $\alpha$ with 5.19and 5.53-fold increase over the control, whereas the truncated promoter had only a 3.43-fold increase over the control. Mut1 promoter responded to TNF $\alpha$ with a 3.92fold increase over the control. These results indicate that induction of Dll4 in hepatocytes is partially NFKBdependent.

\section{HSCs cocultured with DII4-expressing hepatocytes and liver fibroblasts undergo $\mathrm{T}$ lymphopoiesis}

The OP9 cell line was established from newborn calvaria of the $(\mathrm{C} 57 \mathrm{BL} / 6 \mathrm{~J} \times \mathrm{C} 3 \mathrm{H}) \mathrm{F} 2$-op/op mouse deficient in $\mathrm{M}_{-\mathrm{CSF}^{19}}$. OP9-DL1 and OP9-DL4 cells have been frequently used to study the differentiation of mouse and 
a

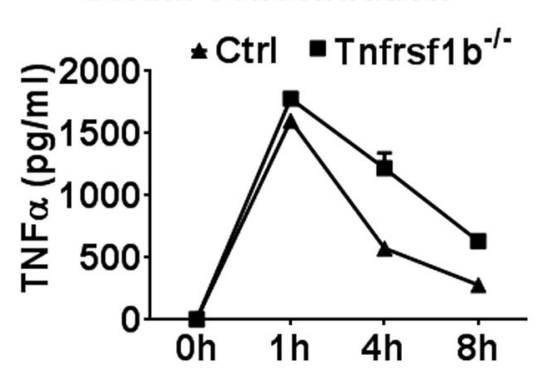

b

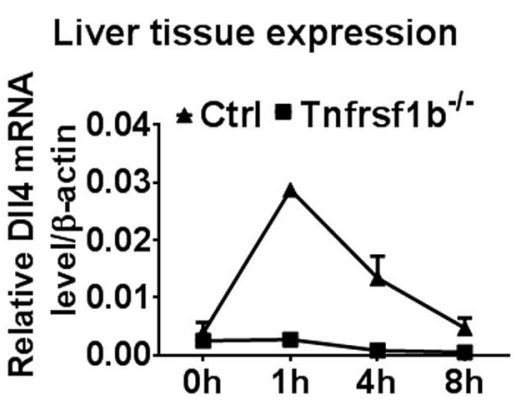

C

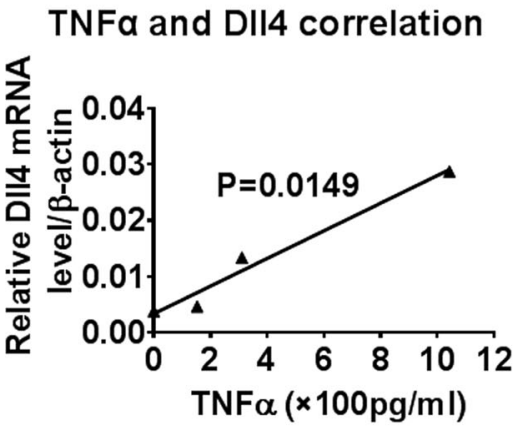

g

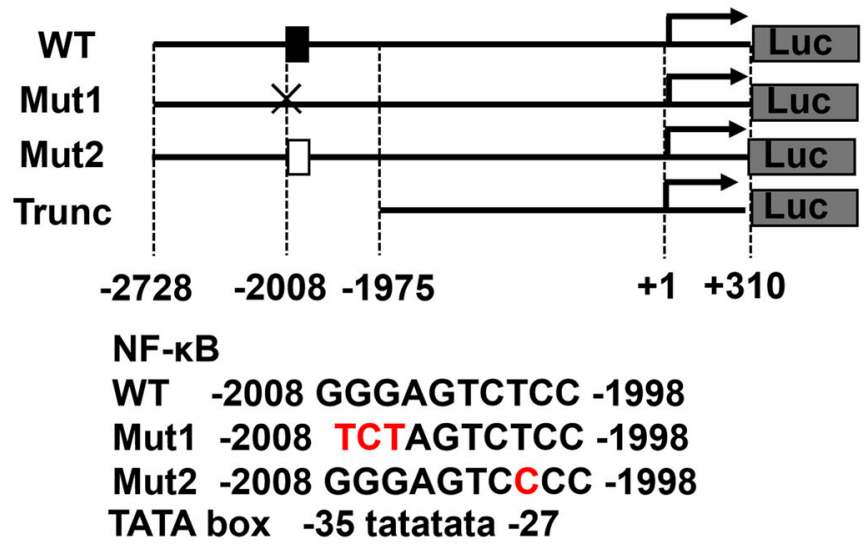

d

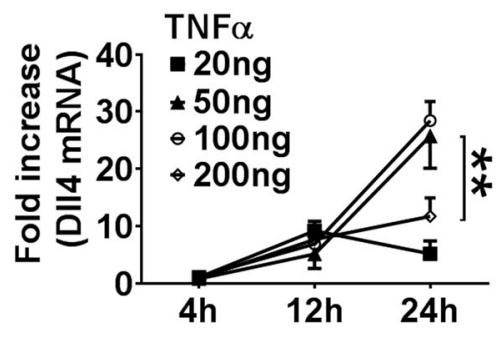

e

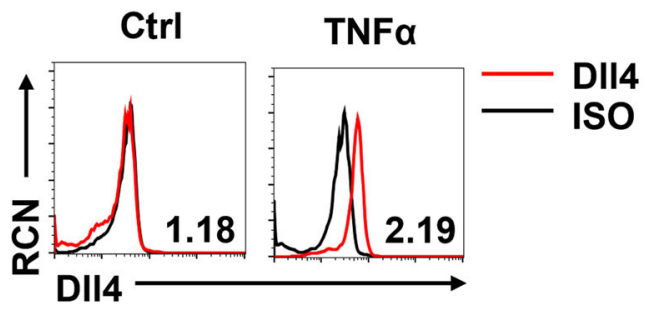

f
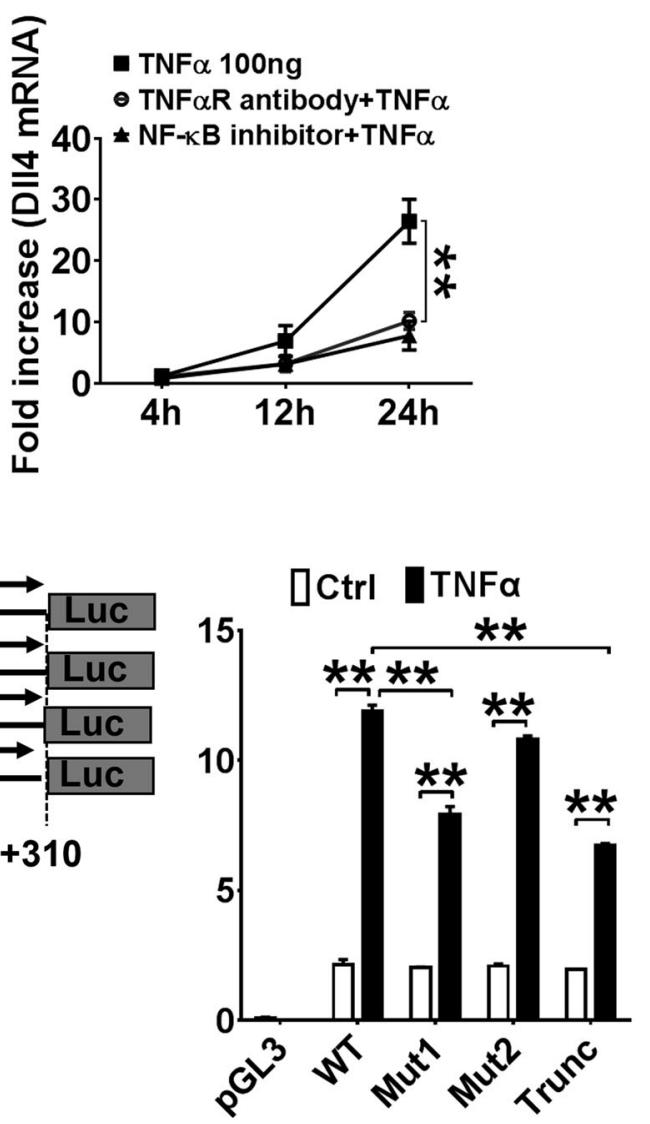
(see figure on previous page)

Fig. 4 Induction of DII4 in fibrotic hepatocytes through an NFKB-dependent mechanism. a Serum TNFa concentrations in normal C57BL/6J mice and Tnfrsfib $b^{-1-}$ mice were detected by ELISA, after LPS were injected by IP. $\mathbf{b}$ Liver tissues were collected and mRNA was harvested for analysis of DII4 expression by qRT-PCR. $\mathbf{c}$ Pearson correlation analysis of the serum TNFa concentrations and DII4 mRNA levels in the liver. $\mathbf{d}$ Primary hepatocytes were treated with TNFa at different concentrations for the indicated times and mRNA was harvested for qRT-PCR analysis. ${ }^{* *} P<0.01$. e Primary hepatocytes were rested or treated with TNFa $(50 \mathrm{ng} / \mathrm{ml})$ for $24 \mathrm{~h}$ and harvested for flow cytometry analysis using either an isotype control or a DII4-APC-specific antibody. f Primary hepatocytes were treated with TNFa $(100 \mathrm{ng} / \mathrm{ml})$ for the indicated times in the presence of control antibody, a blocking antibody to TNFaR, or NF-KB inhibitor JSH-23, and mRNA was harvested for qRT-PCR analysis of DII4 expression. ${ }^{* *} P<0.01$. g The Dll4 promoter containing an NF-KB binding element responds to TNFa. The mouse Dll4 promoter was cloned upstream of the luciferase gene in pGL3-basic vector. The WT and Mut with different mutant NF-KB sites are indicated. A truncated version of the promoter that lacks the NFKB binding site was also generated. Primary hepatocytes were transfected with the control (pGL3-basic) vector, the reporter vectors containing the WT DII4 promoter, or the reporter vectors containing the Dll4 promoter with mutant NFKB binding site. Cells were transfected and rested $48 \mathrm{~h}$ and then treated for $8 \mathrm{~h}$ with TNFa $(100 \mathrm{ng} / \mathrm{ml})$ before lysis and luciferase assay. The results are presented as mean \pm S.E.M. Statistical significance was determined by Student's $t$ test. Significance between samples is indicated in the figures as follows: ${ }^{*} P<0.01$

human T lymphocytes from different sources of stem cells in vitro ${ }^{20-22}$. Since OP9 cells or thymic stromal cells (TSCs) $^{23}$ ectopically expressing Dll4 were sufficient for the induction and sustenance of $\mathrm{T}$-cell development in vitro (Supplementary Fig. 9a, b), whereas ectopic expression of Dll4 in NIH/3T3 and mesenchymal stem cells (MSCs) failed to drive T-lineage development (Supplementary Fig. 9c), we hypothesized that fibrotic liver-associated hepatocytes might have only produced Dll4 to activate the Notch signaling pathway in HSCs, and liver fibroblast cells may have provided the other factors required for HSCs to further differentiate into $\mathrm{T}$ lineage. To determine whether the liver fibroblast cells expressing Dll4 ligands can support the generation of $\mathrm{T}$ cells, we isolated primary LF from fibrotic liver and also obtained pure liver fibroblast with $\alpha$ SMA expression by passaging for five generations (P5 LF) (Supplementary Fig. 10a). We transduced primary and P5 liver fibroblasts with lentiviral puro-Dll4 (LF-Dll4) (Supplementary Fig. 11a), expanded the cells in medium containing puromycin, and examined their ability to initiate and support the differentiation of early $\mathrm{T}$ lineage in vitro. To achieve this, we cocultured HSCs with primary LF-Dll4, P5 LF-Dll4, or OP9-Dll4 and analyzed the differentiation of CD45.1 $1^{+}$cells on day 7 (Fig. 5a). The primary LF-Dll4 cells, like OP9, could readily support the generation of early $\mathrm{T}$-lineage progenitors. In contrast, P5 LF-Dll4 cells did not possess the ability to promote T-cell development. On day 7, primary LF-Dll4 cocultures contained $5.74 \% \mathrm{CD}^{+} 5^{+}$early Tlineage cells (Fig. 5b). However, this effect of primary LFDll4 was inhibited by Notch signaling pathway inhibitor DAPT ( $N$-[N-(3,5-difluorophenacetyl-L-alanyl)]-S-phenylglycine t-butyl ester) (Supplementary Fig. 12a). The primary LF cells derived from fibrotic livers were not capable of promoting T-cell development (Supplementary Fig. 12b). AML12 (alpha mouse liver 12) was a hepatocyte cell line established from CD1 strain. To mimic hepatic fibrotic microenvironment, we established AML12 cells ectopically expressing Dll4 (AML12-Dll4). HSCs cocultured with AML12-Dll4 failed to produce T lineage. However, when HSCs were seeded over AML12-Dll4/ primary LF cells mixed in 1:1 ratio, they were found to give rise to early $\mathrm{T}$-cell progenitors (Fig. $5 \mathrm{c}$ ). This result indicates that Dll4 expressed by hepatocytes alone is not sufficient to drive T-cell development. We then investigated whether soluble Dll4 could also promote T-cell development by adding rDll4 protein into the culture medium of HSCs/primary LF cells coculture system. As shown in Fig. 5d, soluble rDll4 failed to promote Tlineage development.

We next determined whether $\mathrm{T}$ progenitors obtained from these cultures could also give rise to SPs in vivo. To this end, CD45.1 $1^{+} \mathrm{DN} 2\left(\mathrm{CD} 44^{+} \mathrm{CD} 25^{+}\right)$and $\mathrm{CD} 45.1^{+}$ DN3 $\left(\mathrm{CD} 44^{-} \mathrm{CD} 25^{+}\right)$cells were sorted by $\mathrm{CD} 25$ microbeads from CD45.1 ${ }^{+}$HSCs/AML12-Dll4/primary LF cocultured for 7 days (Fig. 5e), and injected via tail vein into 8-week-old CD45.2 $2^{+}$Rag $2^{-1-}$ mice. Flow cytometric analysis showed that, 4 weeks after transfusion, CD45.1 $1^{+}$ CD8 SPs and CD45.1 $1^{+}$CD4 SPs were readily detected in the peripheral blood of the $\mathrm{CD} 45.2^{+} \mathrm{Rag}^{-1-}$ recipient mice (Fig. 5e). These results indicate that progenitors generated from HSCs/ AML12-Dll4/primary LF cocultures could be used for in vivo applications.

These data suggested that Dll4 produced by hepatocytes was important for T-cell development, but liver fibroblasts were also needed for the provision of the other factors required for inducing HSCs to differentiate into T lineage.

\section{SDF-1 plays an essential role in T-lineage development from HSCs}

The ability of primary LF-Dll4 to promote $\mathrm{T}$ lymphopoiesis was lost after passaging for five generations. We wondered if some factors differently expressed between primary LF and P5 LF were responsible for the differential effect. Genes encoding various inflammatory factors and chemotactic/growth factors were analyzed by qPCR. SDF1 was found to be expressed at a much higher level in the 
a

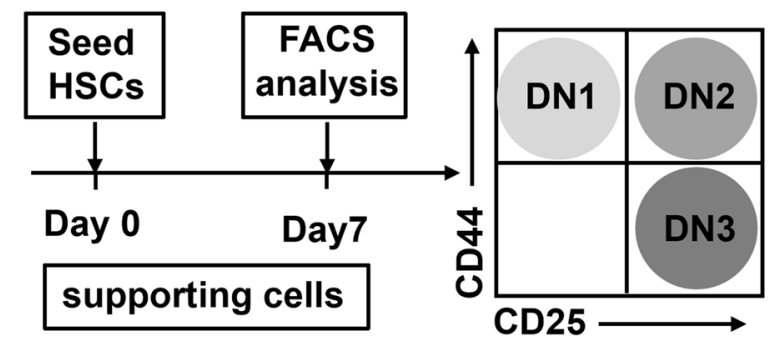

C

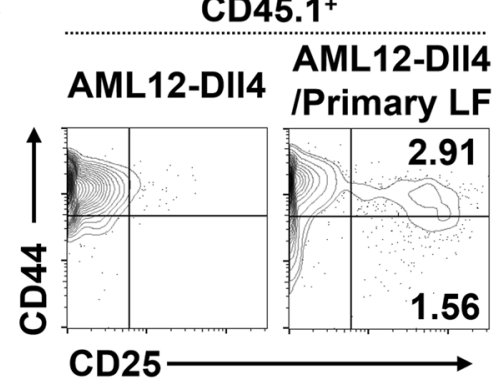

d b

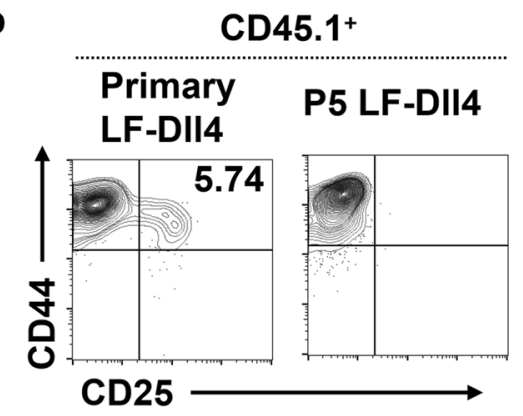

e

CD45.1 ${ }^{+}$

primary LF+ rDIl4 protein OP9-DII4
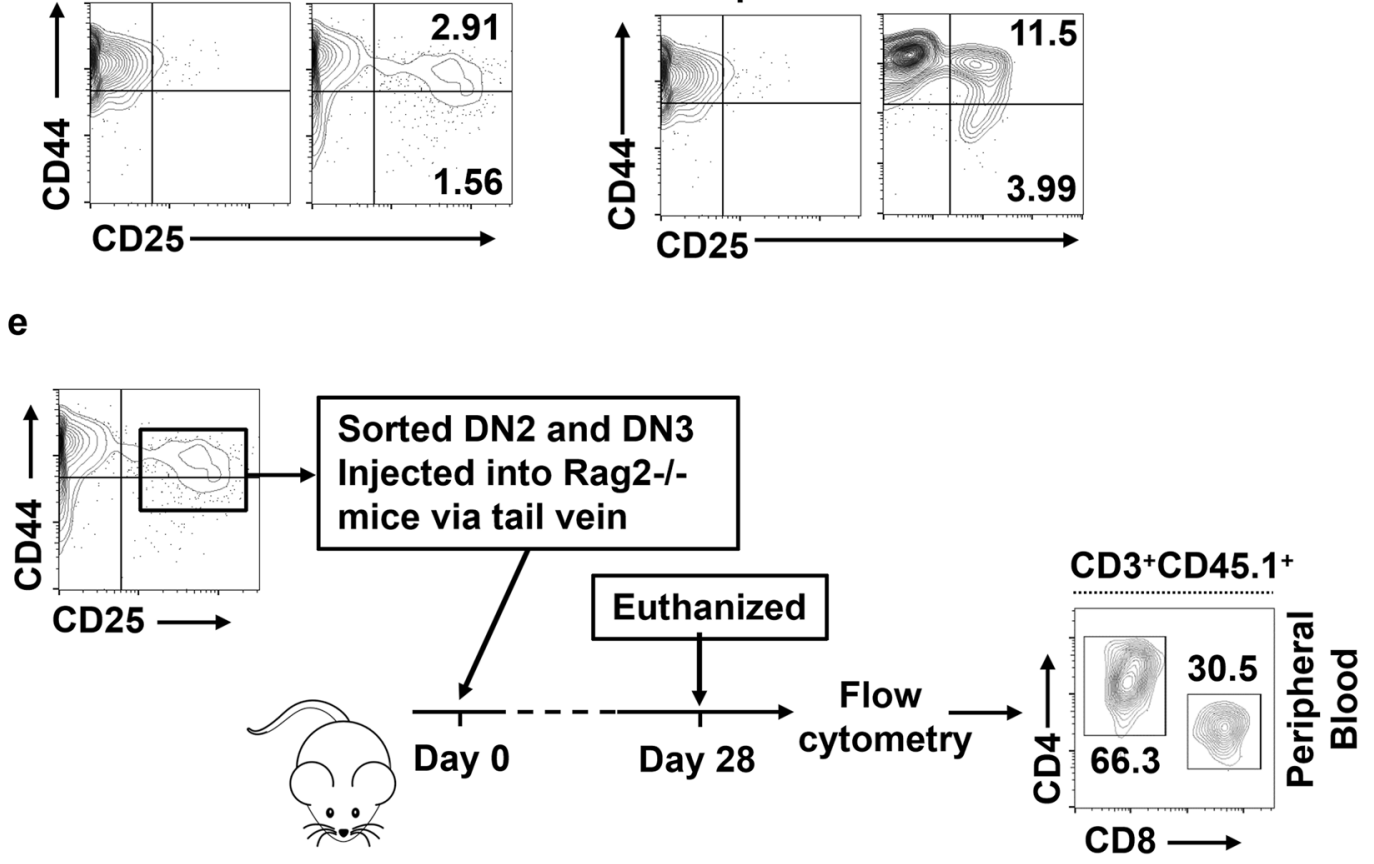

Fig. 5 HSCs cocultured with DII4-expressing hepatocytes and liver fibroblasts undergo T lymphopoiesis. a Schematic representation of the experimental procedures for assessing the development of T-cell lineage in the coculture of HSCs and cells overexpressing DII4. b Sorted HSCs $\left(\mathrm{Lin}^{-} \mathrm{Sca}_{1}^{+} \mathrm{CD} 117^{+}\right)$derived from the bone marrow of CD45.1/C57BL/6J mice were cocultured with primary LF-DIl4 or P5 LF-DII4 cells. HSCs were harvested after 7 days and analyzed by flow cytometry for the surface expression of CD25 and CD44 as indicated. Cells were gated as live (DAPI ${ }^{-}$) and CD45.1 $1^{+}$. Data are representative of at least three independent experiments. $\mathbf{c}$ The expression of CD25 and CD44 was analyzed by FACS on day 7 after HSCs cocultured with AML12-D\|l4 or AML12-D\|l4 (1:1 ratio) mixed with primary LF. d The expression of CD25 and CD44 was analyzed by flow cytometry on day 7 after HSCs cocultured with the indicated cell lines. e Analysis of engraftment and differentiation of in vitro-derived progenitor T-

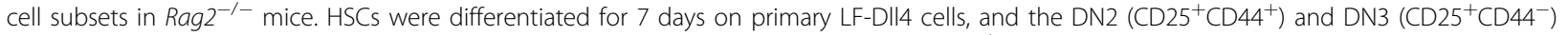
subsets were sorted. Cells $\left(3-5 \times 10^{5}\right)$ were subsequently injected into the tail vein of Rag $2^{-1-}$ mice and the peripheral blood of injected mice was harvested and analyzed for cell surface expression of CD4 and CD8 $(n=5)$ on day 28

cells that are able to support T-lineage development, OP9, TSC, and primary LF, than in nonfunctional cells, including P5 LF, NIH/3T3, AML12, and primary hepatocytes (Fig. 6a). Consistently, we observed that the level of SDF-1 in primary LF cells was gradually downregulated with increasing passages (Fig. 6b). Taken together, these data suggest that SDF-1 derived from primary LF could positively regulate the differentiation of $\mathrm{HSCs}$ to the T lineage.

To determine that the promotion of $\mathrm{T}$ lymphopoiesis by the primary LF-Dll4 was dependent on SDF-1 signaling in our coculture system, we used AMD3100 (Sigma), a specific CXCR4 antagonist that inhibits the binding and function of SDF-1 with high affinity and potency ${ }^{24}$, in the 

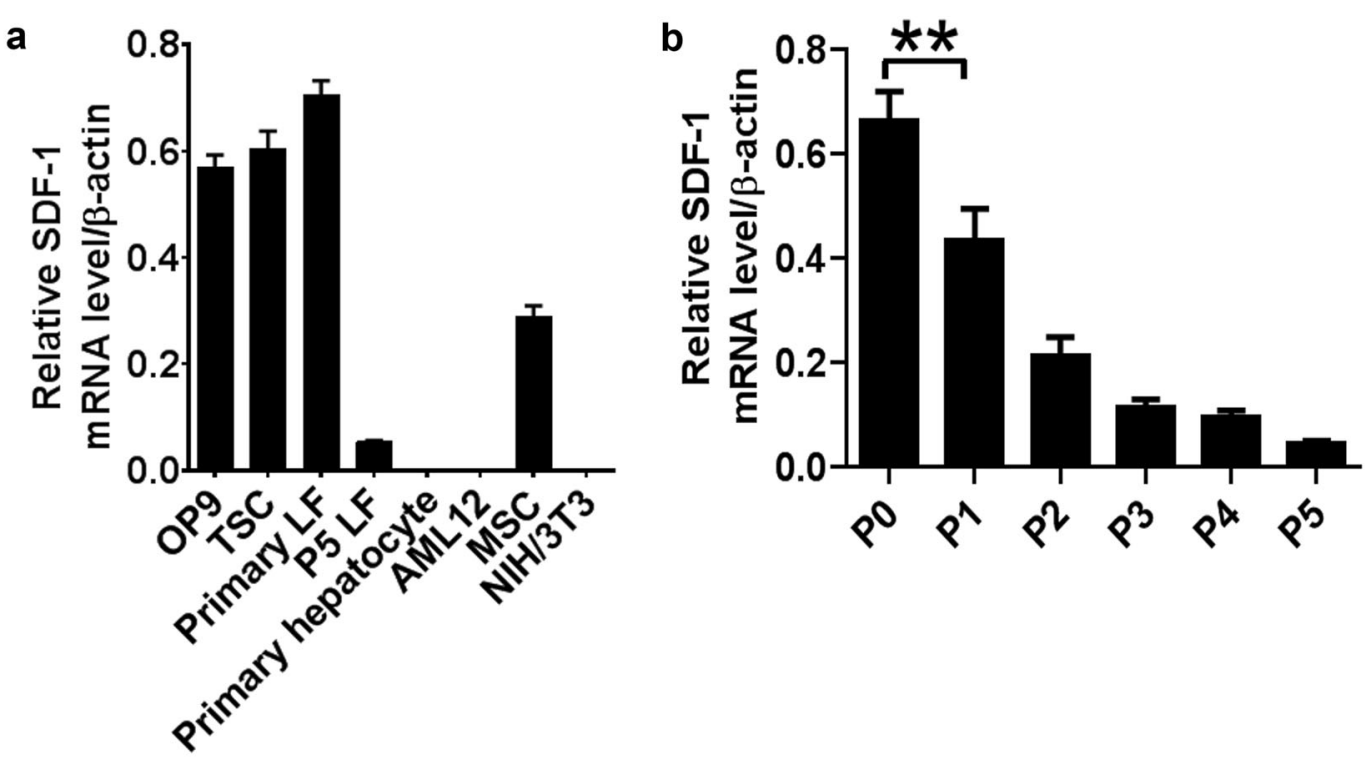

C

CD45

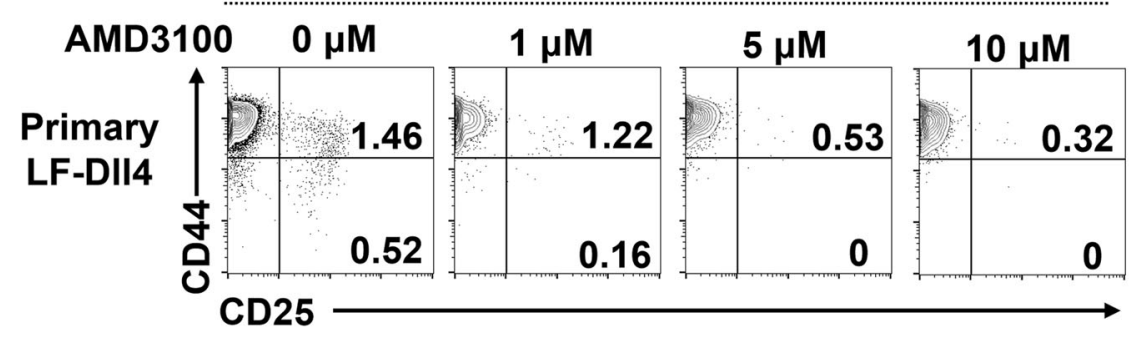

d Mus-164 GCGCTCtgCATCAGTGACGGT

Mus-219 GGTTCTTCGAGAGCCACATCG

Mus-302 GCACGGCTGAAGAACAACAAC

Mus-362 GAGTACCTGGAGAAAGCTTTA

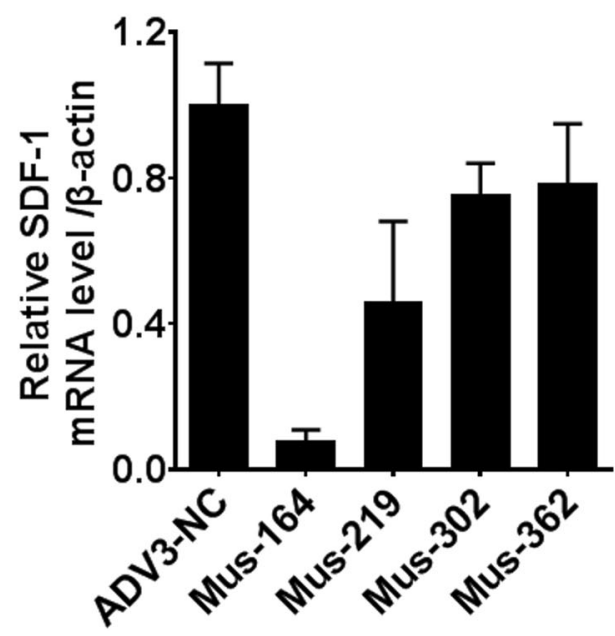

CD45.1+

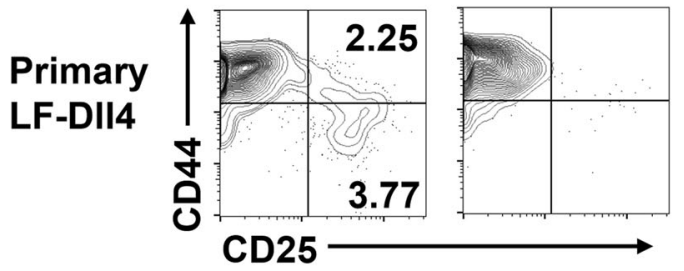

Fig. 6 (See legend on next page.) 
(see figure on previous page)

Fig. 6 SDF-1 expression in primary LF cells plays an essential role in lymphopoiesis in vitro. a Different cultured cells were collected and mRNA was analyzed for the level of SDF-1 expression by qRT-PCR. $\mathbf{b}$ qRT-PCR detected SDF-1 expression in 0-5 successive generations of primary liver fibroblast cells. ${ }^{*} P<0.01$. c The expression levels of CD25 and CD44 were analyzed by flow cytometry on day 7 after coculture of HSCs with primary LF-DII4 with or without different concentration of AMD3100. $\mathbf{d}$ Generation of adenovirus carrying SDF-1 siRNA and transfection of primary liver fibroblast cells. Transfected cells were rested for $48 \mathrm{~h}$ and the level of SDF-1 expression after adenovirus transfection was detected by qRT-PCR, and flow cytometric analysis of the expression of CD25 and CD44 on day 7 after HSCs co-cultured with SDF-1-depleted primary LF-DII4 or control LFDII4

coculture system. As shown in Fig. 6c, the percentages of DN2 and DN3 were gradually decreased with increasing AMD3100 concentrations (Fig. 6c).

We further determined the role of SDF-1 in promoting HSC differentiation to $\mathrm{T}$ lineage by depleting SDF-1 expression in primary LF-Dll4 using adenoviral transfection of SDF-1 small interfering RNA (siRNA). We successfully silenced SDF-1 expression in primary LF cells (Fig. 6d). These SDF-1-deficient primary LF cells were unable to support $\mathrm{T}$ lymphopoiesis.

\section{Discussion}

Liver has been shown to be a major site for extrathymic T-cell development. Previous studies have revealed that bone marrow derived $\mathrm{CD} 117^{+}$precursors are able to migrate to and lodge in the liver during fetal development, as well as in adulthood ${ }^{25}$. CD117 ${ }^{+}$progenitor cells have also been shown to be capable of giving rise to extrathymic T lymphocytes under certain pathological conditions, including infection, autoimmune disease, and malignancy ${ }^{26-28}$. We here showed that mice with liver fibrosis exhibit greater $\mathrm{T}$-lineage reconstitution after irradiation and BMT by the hepatic portal vein, which recapitulates the clinical observations in AIDS patients with liver cirrhosis who received autologous BMT via hepatic portal vein.

The remarkable T-cell reconstitution by BMT via hepatic portal vein in AIDS patients with liver cirrhosis indicates that the direct traffic of T-cell progenitors from bone marrow to thymus is probably blocked. It appears that the hepatic portal vein and the fibrotic liver may have provided an alternate route and a nurturing niche, respectively, for the $\mathrm{T}$ progenitors. The fibrotic liver microenvironment in adult AIDS patients may have reactivated HSCs and directed their T-cell lineage development. Although there is no direct evidence that HIV-1 infection may reduce the seeding of $\mathrm{T}$ progenitors to thymus, it has been reported that the common lymphoid progenitors (CLPs) with reduced CCR7 exhibited impairment in their seeding in thymus ${ }^{29}$. Hematopoietic progenitor cells have been shown to have the potential to generate reservoirs for HIV, and infection and replication of HIV-1 were detected in purified T-cell progenitors of normal human bone marrow ${ }^{30,31}$. HIV-1 accessory protein Vpu downregulates CCR7 on the surface of CD4 ${ }^{+}$ $\mathrm{T}$ cells ${ }^{32}$. Future studies may test whether HIV-1 infection can block T-cell-progenitor seeding to the thymus by downregulating CCR7 expression on CLPs.

Previous studies have shown that coculture of HSCs with OP9 bone marrow stromal cells overexpressing Notch ligands Dll4 enabled T-cell lineage generation in vitro ${ }^{21}$, and there was also report of induction of $\mathrm{T}$-cell development by Dll4-expressing fibroblasts from mouse ear epidermal tissue ${ }^{33}$. The transcription factor FOXN1 was critically required for the development of thymic epithelial cells, and Dll4 was one of the target genes of Foxn $1^{34-36}$. Enforced Foxn1 expression was sufficient to reprogram primary mouse embryonic fibroblasts into functional TECs; these Foxn1 induced TECs upregulated Dll4 expression and supported development of both $\mathrm{CD}^{+}$and $\mathrm{CD}^{+} \mathrm{T}$ cells in vitro ${ }^{37}$. We here show that primary LF with Dll4 OE could also promote T-cell development, but would lose this property after five passages. Hepatocyte cell line AML12 ectopically expressing Dll4 (AML12-Dll4) failed to support T-lineage development, but when mixed with primary LF they could promote $\mathrm{T}$-cell development, indicating that in fibrotic liver microenvironment hepatocytes may activate Notch1 on HSCs' surface, by virtue of the upregulated Dll4, and liver fibroblasts could provide the other factors and cytokines necessary for T-lineage development. When DN2 and DN3 T-cell progenitors generated from HSCs/AML12Dll4/LF cultures were transferred into immunodeficient $\operatorname{Rag} 2^{-1-}$ mice, they differentiated into mature $\mathrm{T}$ cells that can be detected in the peripheral blood of the host.

Previous studies showed that the SDF-1/CXCR4 chemokine system was not required for T-cell development in embryos, but was involved in adult T-cell development $^{38-43}$. SDF-1/CXCR4 also played an important role in the migration of $\mathrm{T}$-cell precursors during development in both fetal and adult thymus ${ }^{44-48}$. Interestingly, SDF- 1 is also a transcriptional target of Foxn $1^{36}$. In the current study, we found that the promotion of T-cell development by LF-Dll4 was abolished when the SDF-1-CXCR4 signaling pathway was blocked or SDF-1 was downregulated by siRNA. SDF-1 was shown to be highly expressed in cells that support T-cell development, including OP9, TSC, and primary LF, but expressed at lower levels in cells 
that lack T-cell supportive effect, including P5 LF, NIH/ 3T3, MSC, AML12, and primary hepatocytes. We also show that SDF-1 expression in primary LF was rapidly downregulated after five passages. These results provided the evidence for the critical role of SDF-1-CXCR4 axis in T-lineage development from HSCs. In summary, we show that liver fibrosis could promote $\mathrm{T}$-cell development by upregulating Dll4 and SDF-1 in liver tissues. This study has provided a mechanistic insight into the clinical efficacy of autologous BMT via hepatic portal vein in patients with AIDS and decompensated liver cirrhosis. It expanded our knowledge of the extrathymic T-cell development under pathological conditions.

\section{Materials and methods \\ Mice}

CD45.2/C57BL/6J, CD45.1/C57BL/6J, and Rag2 ${ }^{-/-}$ mice were purchased from the Shanghai Laboratory Animal Center of Chinese Academy of Sciences, Shanghai, China, and maintained under specific pathogen-free conditions. Mice were maintained in the vivarium of Shanghai Institutes for Biological Sciences. Animals were matched for age and gender in each experiment. The animal protocols for the experiments described in this paper were approved by the Institutional Animal Care and Use Committee of the Institute of Health Sciences, Shanghai Institutes for Biological Sciences of Chinese Academy of Sciences.

\section{Reagents}

Dulbecco's modified eagle medium (DMEM), William's E Medium, Minimum Essential Medium Eagle Alpha ( $\alpha$ MEM), Glutamax, and penicillin/streptomycin were purchased from Invitrogen (Carlsbad, CA, USA). Fetal bovine serum (FBS) was from Thermo Fisher Scientific (Waltham, MA, USA). Anti-mouse CD25-coated and CD140a (PDGFR $\alpha$ )-coated magnetic microbeads were from Miltenyi Biotec (Miltenyi Biotec, Gladbach, Germany). Liver Dissociation Kit and Lineage Cell Depletion Kit were also purchased from Miltenyi Biotec (Miltenyi Biotec, Gladbach, Germany). Insulin-TransferrinSelenium Ethanolamine Solution (ITS-X 100 $\times$ ) was purchased from Basal Media (Shanghai, China). NFkB inhibitor JSH-23 was purchased from Selleck (Houston, TX, USA). Recombinant Dll4 protein, TNFaR specific blocking antibodies, and anti-CD31, anti- $\alpha$ SMA, anti-CK18 antibodies for immunohistochemistry were from Abcam (Cambridge, UK). Anti-Dll4 antibodies for immunohistochemistry were from R\&D system (Minneapolis, MN, USA). Donkey anti-goat IgG secondary antibody conjugated to Alexa Fluor 488 and goat anti-rabbit IgG secondary antibody conjugated to $\mathrm{Cy} 3$ were from Invitrogen (Carlsbad, CA, USA). Biotinylated anti-goat IgG secondary antibody and biotinylated anti-rabbit antibody were from MultiSciences (Hangzhou, China). VECTASTAIN $A B C$ kit and $D A B$ Peroxidase Substrate kit were purchased from vector labs (Burlingame, CA, USA). Bovine serum albumin (BSA), $N$-[ $N$-(3,5-difluorophenacetyl-Lalanyl)]-S-phenylglycine t-butyl ester (DAPT), AMD3100, enzyme collagenase IV, dexamethasone, $\mathrm{CsCl}$, and puromycin were purchased from Sigma-Aldrich (St. Louis, MO, USA). Mouse IL-7 and SCF were purchased from Peprotech (Rochy Hill, NJ, USA). Mouse Flt3L and mouse TNF $\alpha$ were from R\&D system (Minneapolis, MN, USA). RNAprep pure Cell/Bacteria Kit and EndoFree Maxi Plasmid Kit was from Tiangen Biotech (Beijing, China). Primescript RT master Mix and PrimeSTAR ${ }^{\circ}$ GXL DNA Polymerase were from TAKARA (Kusatsu, Shiga Prefecture, Japan). SYBR Green Master Mix was from Roche Diagnostics (Indianapolis, IN, USA). QIAquick Gel extraction kit was from QIAGEN (Hilden, Germany). Coli DH5 $\alpha$ and TransIT $^{\oplus}-2020$ Transfection Reagent were from Invitrogen (USA). KpnI and BamHI restriction enzymes were purchased from NEB (Ipswich, MA, USA). In-Fusion ${ }^{\circ}$ HD Cloning Kit was from Clontech (Mountain View, CA, USA). The kit of Dual-Luciferase Reporter Assay System was purchased from Promega (Madison, WI, USA). The fluorochrome-labeled antibodies (for flow cytometry) were purchased from Biolegend (San Diego, CA, USA).

\section{Cells}

Cell lines of OP9, AML12, and NIH/3T3 were obtained from the Typical Model Cultivation Center of Chinese Academy of Sciences (Shanghai, China). TSCs were derived from thymus of C57BL/6 mice $^{23}$. Mouse MSCs were generated from tibia and femur bone marrow using $6-10$-week-old mice and were used from 10 th to 15 th passage.

Primary mouse liver fibroblasts and P5 mouse liver fibroblasts were prepared as follows: livers were removed from euthanized C57BL/6J mice and were processed to generate single-cell suspensions by Liver Dissociation Kit (Miltenyi Biotec, Germany). Cell suspension was passed through $70 \mu \mathrm{m}$ nylon cell strainer (FALCON, USA) and parenchymal mouse liver cells were removed by centrifugation and cells were then resuspended in the MACS buffer [Phosphate-buffered saline (PBS) pH 7.2, and 0.5\% BSA, 1 mM EDTA]. CD140a (PDGFR $\alpha$ ) MicroBead Kit was used to magnetically separate $\mathrm{CD} 140 \mathrm{a}^{+}$cells and resulting cells were cultured in DMEM [supplemented with $10 \%$ FBS, $2 \mathrm{mM}$ Glutamax, $2 \mathrm{mM}$ 2-mercaptoethanol, and penicillin $(100 \mathrm{U} / \mathrm{ml}) /$ streptomycin $(100 \mathrm{mg} / \mathrm{ml})]$. Cells were allowed to grow for 10 days to establish a cell culture of primary LF.

Primary hepatocytes were isolated by two-step collagenase perfusion of normal C57BL/6J liver. In brief: $30 \mathrm{ml}$ EGTA buffer was perfused through the portal vein 
of anesthetized mice and then changed to $40 \mathrm{ml}$ collagenase solution (enzyme collagenase IV $0.75 \mathrm{mg} / \mathrm{ml}$ in PBS) perfused in for $\sim 5 \mathrm{~min}$. The entire liver was removed and transferred to a Petri dish containing collagenase solution (enzyme collagenase IV $0.08 \mathrm{mg} / \mathrm{ml}$ in PBS) at $37^{\circ} \mathrm{C} 100 \mathrm{rpm} 5 \mathrm{~min}$. The gallbladder was cut out and the liver lobes were separated using two pairs of forceps. The crude hepatocytes preparation was filtered through a gauze mesh filter $(100 \mu \mathrm{m}$ in diameter) and the resulting cell suspension was transferred into two $50-\mathrm{ml}$ sterile tubes and centrifuged at $50 \times \mathrm{g}$ for $3 \mathrm{~min}$. The cell pellets were washed three to four times in PBS by centrifuging at $50 \mathrm{~g}$ for $2 \mathrm{~min}$. The cells were resuspended in William's $\mathrm{E}$ Medium [supplemented with $10 \%$ FBS, $1 \times$ InsulinTransferrin-Selenium Ethanolamine Solution (ITS-X $100 \times), 40 \mathrm{ng} / \mathrm{ml}$ dexamethasone, $2 \mathrm{mM}$ Glutamax, and penicillin $(100 \mathrm{U} / \mathrm{ml}) /$ streptomycin $(100 \mathrm{mg} / \mathrm{ml})]$. The cells were inoculated into $35 \mathrm{~mm}$ tissue culture dishes at $6 \times 10^{5}$ of hepatocytes suspension per dish. After 6-8 h, the supernatant and unattached cells were discarded, and the adherent cells were then fed with fresh William's E Medium. Cells culture continued as required.

\section{$\mathrm{CCl}_{4}$ treatment and $\mathrm{BMT}$}

Six-week-old male CD45.2/C57BL6/J mice were treated with $10 \mathrm{~mL} / \mathrm{kg} \mathrm{CCl}{ }_{4}$ dissolved in corn oil (1:5) twice a week for 8 weeks. Mice were subjected to 6 Gy sublethal irradiation $24 \mathrm{~h}$ before BMT $\left(3 \times 10^{6} \mathrm{BMCs}\right)$ from CD45.1/C57BL6/J mice in $200 \mu$ l PBS were injected into spleen to allow liver entry through the hepatic portal vein). Mice were continually treated with $\mathrm{CCl}_{4}$ for 4 weeks and were then euthanized to assess the extent of liver fibrosis. Peripheral blood, spleen, and thymus were collected to assess the stages of T-cell development.

\section{Preparation of BMCs}

For BMCs isolation, CD45.1/C57BL6/J congenic mice (6-week-old) were euthanized by cervical dislocation followed by limbs removal. BMCs from CD45.1/C57BL6/J mice were flushed with DMEM containing 10\% FBS from the medullary cavities of tibias and femurs using a $25-\mathrm{G}$ needle.

\section{Immunohistochemistry}

Frozen sections of mouse liver were subjected to immunohistochemical staining using anti-CD31, antiaSMA, anti-CK18, and anti-Dll4 antibodies. In brief, sections were washed three times and treated with $0.1 \%$ trypsin for antigen unmasking and $3 \% \mathrm{H}_{2} \mathrm{O}_{2}$ to block endogenous peroxidase activity. Sections were then blocked with reagent containing 5\% BSA in PBS for $1 \mathrm{~h}$. Goat polyclonal anti-Dll4 antibody (R\&D; AF1389-SP) was used at 1:100 dilution, coupled with donkey anti-goat
IgG secondary antibody conjugated to $\mathrm{Cy} 3$ at 1:500 dilution. Rabbit polyclonal anti- $\alpha$ SMA antibody (Abcam; ab5694) was used at 1:200 dilution, rabbit polyclonal antiCD31 antibody (Abcam; ab28364) was used at 1:50 dilution, and rabbit polyclonal anti-CK18 (Abcam; ab24561) was used at 1:200 dilution, coupled with goat anti-rabbit IgG secondary antibody conjugated to Alexa Fluor 488 at 1:1000 dilution. Nuclei were stained using DAPI (Sigma; D9542).

Immunohistochemical staining of serial sections of human cirrhotic liver samples in paraffin, obtained from Shanghai Public Health Clinical Center, was performed using antibodies to CD31, $\alpha$ SMA, CK18, and Dll4. Goat polyclonal anti-Dll4 antibody (R\&D; AF1389-SP) was used at 1:50 dilution, coupled with biotinylated anti-goat IgG secondary antibody at 1:500 dilution. Rabbit polyclonal anti- $\alpha$ SMA antibody (Abcam; ab5694) was used at 1:250 dilution, rabbit polyclonal anti-CD31 antibody (Abcam; ab28365) was used at 1:50 dilution, and rabbit polyclonal anti-CK18 (Abcam; ab24561) was used at 1:500 dilution, coupled with biotinylated anti-rabbit antibody at 1:500 dilution. After antibody staining, sections were washed in PBST, treated with VECTASTAIN ABC kit for biotin-streptavidin signal amplification, and subsequently visualized by DAB Peroxidase Substrate kit and nuclei were stained by hematoxylin stain.

\section{Adenovirus-mediated DII4 OE in liver}

The AdEasyTM adenoviral vector system was utilized to construct the adenovirus expression vectors ${ }^{49}$. For Dll4 expression, the encoding sequences were subcloned into pTrack-CMV vector and recombined with pAdEasy vector. The adenoviruses were packaged in HEK293A cells and purified with $\mathrm{CsCl}$ ultracentrifugation. The viruses were titrated and administered via caudal vein injection $\left(10^{9} \mathrm{pfu}\right.$ viruses per mouse). Four days later, mouse liver tissues were collected and the level of Dll4 expression was examined by qRT-PCR and immunohistochemistry.

\section{Generation of Dll4-overexpressing cells}

OP9, MSC, NIH/3T3, TSC, AML12, and mouse liver fibroblasts were transduced to express Dll4, as described for the OP9-DL1 and OP9-DL4 cells ${ }^{50}$. Briefly, the lentiviral vector PLVX-IRES-Puro containing the Dll4 cDNA sequence was independently transfected into HEK-293T cells along with a plasmid pMD2.G and psPAX2 in DMEM. Lentiviral particles produced and released into the supernatant were used to infect the packaging cell line. Transfected cells were selected by puromycin at $1 \mu \mathrm{g} / \mathrm{ml}$.

\section{Adenovirus particles for siRNA for SDF-1}

SDF-1-specific and control siRNA adenovirus particles were prepared by GenePharma (Shanghai, China, http:// www.genepharma.com). 


\section{Flow cytometry}

For the analysis of cell surface molecules on mouse cells, directly conjugated antibodies CD25-FITC, CD44-PE, and CD45.1-APC were used for analyzing the differentiation of HSCs cocultured with Dll4 OE cells on a GALLIOS flow cytometer (Beckman Coulter, Brea, CA, USA) using GALLIOS software.

For in vivo experiments, peripheral blood was collected from each mouse before euthanizing; spleen and thymus were also collected for lymphocyte staining. Tlymphocytic population changes were quantified by flow cytometry. Thymocytes were stained with antibodies to CD45.1-APC, CD45.2-Alex700, CD25-PE, and CD44PerCP-Cy5.5, and a lineage-FITC mix containing antibodies to the following markers: $\mathrm{CD} 4, \mathrm{CD} 8 \alpha, \mathrm{TCR} \beta$, TCR $\gamma \delta$, CD19, NK1.1, DX5, Gr1 (Ly6C/G), CD11b, and Ter119 to facilitate gating and analyzing on stages of DN cells. To assess DP and SP cells, thymocytes were stained for CD45.1-APC, CD45.2-Alex700, CD3-PE, CD4-PerCPCy5.5, and CD8-FITC. Lymphocytes in peripheral blood and spleen were stained for CD45.1-APC, CD45.2Alex700, CD3-PE, CD4-PerCP-Cy5.5, and CD8-FITC to assess different T-lymphocyte populations. To characterize Dll4, OE cells were stained with anti-Dll4-APC.

\section{Coculture of hematopoietic progenitor cells with DIl4 overexpressing cells}

Hematopoietic progenitor cells were isolated from 8 weeks CD45.1/C57BL/6J BMCs. Lin $^{-}$bone marrow progenitor cells were enriched by Lineage Cell Depletion Kit and then FACS-sorted for the expression of CD117 and Sca- 1 by flow cytometry. Mouse HSCs $\left(1 \times 10^{5} /\right.$ well in six-well tissue-culture plates, were incubated with different Dll4-overexpressing cells (semiconfluent) in $\alpha M E M$ [supplemented with $15 \% \mathrm{FBS}$, penicillin $(100 \mathrm{U} / \mathrm{ml})$, streptomycin $(100 \mathrm{mg} / \mathrm{ml}), 10 \mathrm{ng} / \mathrm{ml} \mathrm{IL-7,} 10 \mathrm{ng} / \mathrm{ml}$ Flt3L, and $50 \mathrm{ng} / \mathrm{ml} \mathrm{SCF}]^{22}$. Cells were harvested on day 7 for analysis or further passaged onto fresh plates containing Dll4 overexpressing cells for analysis on days 10 and 13 .

\section{Adoptive transfer of progenitor cells}

Mouse HSCs were cocultured with AML-Dll4/primary $\mathrm{LF}$ in a 10-cm plate, in $\alpha M E M$ supplemented with $10 \mathrm{ng} /$ $\mathrm{ml} \mathrm{IL-7,} 10 \mathrm{ng} / \mathrm{ml} \mathrm{Flt3L}$, and $50 \mathrm{ng} / \mathrm{ml} \mathrm{SCF}$ for 8 days. DN2 $\left(\mathrm{CD}_{4} 4^{+} \mathrm{CD} 25^{+}\right)$and DN3 $\left(\mathrm{CD} 44^{-} \mathrm{CD} 25^{+}\right)$cells from the coculture were sorted by $\mathrm{CD} 25$ MicroBeads, and $3-5 \times 10^{5}$ DN2 cells were injected into the tail vein of 4-8-week-old Rag2 ${ }^{-/-}$mice. The peripheral blood of the injected mice was examined by flow cytometry for the presence of $\mathrm{T}$ cells on day 28 postinjection.

\section{qRT-PCR}

Total RNA was isolated using RNAprep pure Cell/ Bacteria Kit, and reverse transcribed into cDNA using primescript RT master Mix. Gene probes were used with SYBR Green Master Mix and a 7900HT Fast Real-Time PCR system (Applied Biosystems, Foster City, CA, USA). Total amount of mRNA was normalized to endogenous $\beta$-actin mRNA. Sequences of primer pairs were listed in Supplementary Table 1.

\section{Cloning of DII4 promoter sequence}

Genomic DNA was isolated from C57BL/6J primary hepatocytes by standard protocol. Using the GenBank sequence for mouse chromosome 2 as a template, we designed two steps PCR: first-step primers Dll4p-out-F: TTCCTCTCTCCTCCCTCAGC and Dll4p-Out-R: TGACGACGAAGGAGTTGGTG amplify $4499 \mathrm{bp}$ of sequence from -3789 to $+710 \mathrm{bp}$ of Dll4 transcriptional start site. The PCR products of the first step were used as templates for the second-step primer contained restriction enzyme site linkers as follows: Dll4-prom-KpnI-F: CGCGGTACCTTCTGCATAATGGGAGAAACTG and Dll4-prom-BamHI-R: CCGCGGGATCCCTCCACTCCG GGACTCCGAA amplify $3038 \mathrm{bp}$ of sequence from -2728 to +310 bp of the Dll4 transcriptional start site. PCR was performed on a Tetrad 2 peltier thermal cycler (Bio-RAD, Hercules, CA, USA) using genomic DNA and PrimeSTAR GXL DNA Polymerase with the following parameters: $98^{\circ} \mathrm{C}$ for $2 \mathrm{~min}(1 \mathrm{cycle}), 98^{\circ} \mathrm{C}$ for $10 \mathrm{~s}, 60^{\circ} \mathrm{C}$ for $15 \mathrm{~s}$, and $68^{\circ} \mathrm{C}$ for $4 \mathrm{~min} 30 \mathrm{~s}$ in the first step, or $2 \mathrm{~min}$ $54 \mathrm{~s}$ in the second step (30 cycles). The second-step PCR products were electrophoretically separated on $0.8 \%$ agarose gels, and the appropriate-sized band cut out and purified using the QIAquick Gel extraction kit. Purified second-step PCR products were digested with KpnI and BamHI restriction enzymes and ligated into KpnI and BamHI-digested pGL3-basic Luciferase Reporter vector (Promega, USA). The putative NFkB binding site in the Dll4 promoter was mutated from (mutated bases bold and italicized) GGGAGTCTCC to TCTAGTCTCC and GGGAGTCTCC to GGGAGTCCCC, using the InFusion ${ }^{\oplus}$ HD Cloning Kit. All ligation reaction products were transformed into E.coli DH5 $\alpha$, and amplified and purified by EndoFree Maxi Plasmid Kit. The constructs were verified by sequencing (Sangon Biotech, Shanghai, China) and subsequent analysis using FinchTV 1.4 software (Geospiza Inc, Seattle, WA, USA). The putative transcription factor binding sites were identified using the TRANSFAC Database (www.gene-regulation.com).

\section{Transfections and luciferase reporter assays}

Confluent C57BL/6J primary hepatocytes grown in 6well or $10-\mathrm{cm}$ plates were transfected according to the manufacturer's instructions, with modifications using TransIT $^{\circ}-2020$ Transfection Reagent. Briefly, $70-80 \%$ confluent C57BL/6J primary hepatocytes in 24-well plates were incubated with $0.5 \mathrm{ml}$ transfection cocktail 
containing $500 \mathrm{ng}$ pGL3-vector with the Dll4 promoter sequence and $50 \mathrm{ng}$ Renila plasmid DNA per well. After $24 \mathrm{~h}$, the transfection cocktail was replaced with fresh culture medium before $100 \mathrm{ng} / \mathrm{ml}$ TNF $\alpha$ treatment. Eight hours later, the cells were lysed and the reporter activities were calculated according to the protocol provided with the kit of Dual-Luciferase Reporter Assay System (Promega; E1910).

\section{Statistical analysis}

Statistical analysis of all paired experiments was analyzed by two-tailed Student's $t$ test. All graphs were represented by mean and standard error of the mean, where n.s. $=P>$ $0.05 ;{ }^{*} P<0.05 ;{ }^{* *} P<0.01 ;{ }^{* * * *} P<0.001$; unless otherwise stated. All experiments were performed at least three times with similar results, except where indicated.

\section{Acknowledgements}

This study was supported by grants from the National Key R\&D Program of China (2018YFA0107500), the National Natural Science Foundation of China $(81530043,81330046,81702869,81861138015,31771641$, and 81571612), the Youth Innovation Promotion Association research fund from the Chinese Academy of Sciences, a start-up fund from Soochow University, the Department of Science and Technology of Jiangsu Province research fund (BE2016671), the Project funded by China Postdoctoral Science Foundation (2016M591917), and the Postdoctoral Science Foundation of Jiangsu Province (1501063A and 1601027C).

\section{Author details \\ ${ }^{1}$ The First Affiliated Hospital of Soochow University, Institutes for Translational Medicine, State Key Laboratory of Radiation Medicine and Protection, Key Laboratory of Stem Cells and Medical Biomaterials of Jiangsu Province, Soochow University Medical College, Suzhou, China. ${ }^{2}$ Key Laboratory of Tissue Microenvironment and Tumor, Institute of Health Sciences, Shanghai Institutes for Biological Sciences, Chinese Academy of Sciences, University of Chinese Academy of Sciences, Shanghai, China. ${ }^{3}$ Department of Surgery, Shanghai Public Health Clinical Center Fudan University, Shanghai, China. ${ }^{4}$ Department of Gastroenterology, Changhai Hospital, Second Military Medical University, Shanghai, China}

\section{Conflict of Interest}

The authors declare that they have no conflict of interest.

\section{Publisher's note}

Springer Nature remains neutral with regard to jurisdictional claims in published maps and institutional affiliations.

Supplementary Information accompanies this paper at (https://doi.org/ 10.1038/s41419-019-1630-1).

Received: 31 January 2019 Revised: 22 April 2019 Accepted: 29 April 2019 Published online: 05 June 2019

\section{References}

1. Moir, S., Chun, T. W. \& Fauci, A. S. Pathogenic mechanisms of HIV disease. Annu. Rev. Pathol. 6, 223-248 (2011).

2. Castelo-Branco, C. \& Soveral, I. The immune system and aging: a review. Gynecol. Endocrinol. 30, 16-22 (2014).

3. Williams, K. M., Hakim, F. T. \& Gress, R. E. T cell immune reconstitution following lymphodepletion. Semin. Immunol. 19, 318-330 (2007).

4. Mackall, C. L. et al. Prolonged CD4 depletion after sequential autologous peripheral blood progenitor cell infusions in children and young adults. Blood 96, 754-762 (2000).
5. Nordøy, T. et al. Humoral immunity to viral and bacterial antigens in lymphoma patients 4-10 years after high-dose therapy with ABMT. Serological responses to revaccinations according to EBMT guidelines. Bone Marrow Transplant. 28, 681-687 (2001).

6. Small, T. et al. Comparison of immune reconstitution after unrelated and related T-cell-depleted bone marrow transplantation: effect of patient age and donor leukocyte infusions. Blood 93, 467-480 (1999).

7. Durand, C. \& Flexner, C. HIV cure: knocking on the door. Clin. Pharmacol. Ther. 93, 382-384 (2013).

8. Liu, B., Chen, X., Wang, Y. \& Shi, Y. Curative effect of hepatic portal venous administration of autologous bone marrow in AIDS patients with decompensated liver cirrhosis. Cell Death Dis. 4, e739 (2013).

9. Rabson, A. B. Bringing back the help: autologous bone marrow infusion restores CD4+ T cells in AIDS patients with chronic liver disease. Cell Death Dis. 4, e849 (2013).

10. Atamas, S. P. Principles of adaptive immunity. in Rheumatology 6th edn (eds Hochberg, M. C., Silman, A. J., Smolen, J. S., Weinblatt, M. E., \& Weisman, M. H.). 119-126 (Elsevier Inc, Philadelphia, 2015).

11. Blom, B. \& Spits, H. Development of human lymphoid cells. Annu. Rev. Immunol. 24, 287-320 (2006).

12. Germain, R. N. T-cell development and the CD4-CD8 lineage decision. Nat. Rev. Immunol. 2, 309-322 (2002).

13. Weinreich, M. A. \& Hogquist, K. A. Thymic emigration: when and how T cells leave home. J. Immunol. 181, 2265-2270 (2008).

14. Sambandam, A. et al. Notch signaling controls the generation and differentiation of early T lineage progenitors. Nat. Immunol. 6, 663-670 (2005).

15. Tan, J. B., Visan, I., Yuan, J. S. \& Guidos, C. J. Requirement for Notch1 signals at sequential early stages of intrathymic T cell development. Nat. Immunol. 6, 671-679 (2005).

16. Visan, I., Yuan, J. S., Tan, J. B., Cretegny, K. \& Guidos, C. J. Regulation of intrathymic T-cell development by Lunatic Fringe-Notch1 interactions. Immunol. Rev. 209, 76-94 (2006).

17. Rothenberg, E. V., Zhang, J. \& Li, L. Multilayered specification of the T-cell lineage fate. Immunol. Rev. 238, 150-168 (2010).

18. Love, P. E. \& Bhandoola, A. Signal integration and crosstalk during thymocyte migration and emigration. Nat. Rev. Immunol. 11, 469-477 (2011).

19. Gao, J. et al. Characterization of OP9 as authentic mesenchymal stem cell line. J. Genet. Genom. 37, 475-482 (2010).

20. de Pooter, R. \& Zúñiga-Pflücker, J. C. T-cell potential and development in vitro: the OP9-DL1 approach. Curr. Opin. Immunol. 19, 163-168 (2007).

21. Holmes, R. \& Zúñiga-Pflücker, J. C. The OP9-DL1 system: generation of Tlymphocytes from embryonic or hematopoietic stem cells in vitro. Cold Spring Harb. Protoc. 2009, pdb.prot5156 (2009)

22. Shukla, S. et al. Progenitor T-cell differentiation from hematopoietic stem cells using Delta-like-4 and VCAM-1. Nat. Methods 14, 531-538 (2017).

23. Chen, P. et al. Established thymic epithelial progenitor/stem cell-like cell lines differentiate into mature thymic epithelial cells and support T cell development. PLOS ONE 8, e75222 (2013).

24. Rosenkilde, M. M. et al. Molecular mechanism of amd3100 antagonism in the cxcr4 receptor transfer of binding site to the cxcr3 receptor. J. Biol. Chem. 279, 3033-3041 (2004).

25. Shimizu, T. et al. Organ specificity of c-kit+ lymphoid precursors in the liver, thymus, andbone marrow. Eur. J. Haematol. 64, 416-425 (2000).

26. Abo, T. Extrathymic pathways of T-cell differentiation and immunomodulation. Int. Immunopharmacol. 1, 1261-1273 (2001).

27. Abo, T., Kawamura, T. \& Watanabe, H. Physiological responses of extrathymic T cells in the liver. Immunol. Rev. 174, 135-149 (2000).

28. Kong, M. et al. Hepatic carcinoma with indolent T-lymphoblastic proliferation (iT-LBP). Int. J. Clin. Exp. Pathol. 11, 1674-1678 (2018).

29. Vionnie, $W$. et al. Specific bone cells produce DLL4 to generate thymusseeding progenitors from bone marrow. J. Exp. Med. 212, 759-774 (2015).

30. Folks, T. M. et al. Infection and replication of HIV-1 in purified progenitor cells of normal human bone marrow. Science 242, 919-922 (1988).

31. McNamara, L. A. \& Collins, K. L. Hematopoietic stem/precursor cells as HIV reservoirs. Curr. Opin. HIV AIDS 6, 43-48 (2011).

32. Ramirez, P. W. et al. Downmodulation of CCR7 by HIV-1 Vpu results in impaired migration and chemotactic signaling within CD4+ T cells. Cell Rep. 7, 2019-2030 (2014).

33. Mohtashami, M., Shah, D. K., Kianizad, K, Awong, G. \& Zúñiga-Pflücker, J. C. Induction of T-cell development by Delta-like 4-expressing fibroblasts. Int. Immunol. 25, 601-611 (2013). 
34. Blackburn, $\mathrm{C}$. et al. The nu gene acts cell-autonomously and is required for differentiation of thymic epithelial progenitors. Proc. Natl Acad. Sci. USA 93 5742-5746 (1996).

35. Nehls, M. et al. Two genetically separable steps in the differentiation of thymic epithelium. Science 272, 886-889 (1996).

36. Žuklys, S. et al. Foxn1 regulates key target genes essential for T cell development in postnatal thymic epithelial cells. Nat. Immunol. 17, 1206-1215 (2016).

37. Bredenkamp, N. et al. An organized and functional thymus generated from FOXN1-reprogrammed fibroblasts. Nat. Cell Biol. 16, 902-908 (2014).

38. Nagasawa, T. et al. Defects of B-cell lymphopoiesis and bone-marrow myelopoiesis in mice lacking the CXC chemokine PBSF/SDF-1. Nature $\mathbf{3 8 2}$ 635-638 (1996).

39. Tachibana, K. et al. The chemokine receptor CXCR4 is essential for vascularization of the gastrointestinal tract. Nature 393, 591-594 (1998).

40. Zou, Y.-R., Kottmann, A. H., Kuroda, M., Taniuchi, I. \& Littman, D. R. Function of the chemokine receptor CXCR4 in haematopoiesis and in cerebellar development. Nature 393, 595 (1998).

41. Ma, Q. et al. Impaired B-lymphopoiesis, myelopoiesis, and derailed cerebellar neuron migration in CXCR4-and SDF-1-deficient mice. Proc. Natl Acad. Sci. USA 95, 9448-9453 (1998).

42. Kawabata, K. et al. A cell-autonomous requirement for CXCR4 in long-term lymphoid and myeloid reconstitution. Proc. Natl Acad. Sci. 96, 5663-5667 (1999).
43. Onai, $\mathrm{N}$. et al. Impairment of lymphopoiesis and myelopoiesis in mice reconstituted with bone marrow-hematopoietic progenitor cells expressing SDF-1-intrakine. Blood 96, 2074-2080 (2000).

44. Kim, C. H., Pelus, L. M., White, J. R. \& Broxmeyer, H. E. Differential chemotactic behavior of developing $T$ cells in response to thymic chemokines. Blood 91, 4434-4443 (1998).

45. Zaitseva, M. B. et al. CXCR4 and CCR5 on human thymocytes: biological function and role in HIV-1 infection. J. Immunol. 161, 3103-3113 (1998).

46. Suzuki, G. et al. Pertussis toxin-sensitive signal controls the trafficking of thymocytes across the corticomedullary junction in the thymus. J. Immunol. 162 5981-5985 (1999).

47. Aiuti, A. et al. Expression of CXCR4, the receptor for stromal cell-derived factor1 on fetal and adult human lymphohematopoietic progenitors. Eur. J. Immunol. 29, 1823-1831 (1999).

48. Campbell, J. J., Pan, J. \& Butcher, E. C. Cutting edge: developmental switches in chemokine responses during T cell maturation. J. Immunol. 163, 2353-2357 (1999).

49. Luo, J. et al. A protocol for rapid generation of recombinant adenoviruses using the AdEasy system. Nat. Protoc. 2, 1236-1247 (2007).

50. Mohtashami, M. et al. Direct comparison of Dll1-and Dll4-mediated Notch activation levels shows differential lymphomyeloid lineage commitment outcomes. J. Immunol. 185, 867-876 (2010). 